\title{
Cancer and COVID-19: how understanding grief helps the pandemic frontlines
}

\author{
A.M. Kahn MD* and R. Andrews MS MD*
}

I first heard of Dr. Elisabeth Kübler-Ross in medical school, when learning how to deliver bad news. The lesson came from a woman who would become be my lifelong mentor back home. She was a medical oncologist and beautiful human being who inspired me to pursue her path by effortlessly turning the painful and rewarding experience of caring for cancer patients into a thing of beauty. She introduced me to the Swiss-American psychiatrist who designed the "Kübler-Ross model" in her 1969 book On Death and Dying, which allowed us to understand grief. Kübler-Ross was able to turn a natural, but also difficult, human process into a somewhat predictable pattern, helping doctors to navigate through the journey hand-in-hand with patients and families.

My years of training first as an internal medicine resident, then as a medical oncology fellow, and finally as a breast cancer fellow provided me with years to mature those skills imbued in me. I learned to support patients' relatives with empathy through their most anguished times after losing their loved ones. When I moved to the United States, my path was set on practicing as a medical oncologist, and so I restarted the internal medicine residency. I would never have thought we would go through what the world is now seeing with the coronavirus disease 2019 (COVID-19) pandemic.

As a breastfeeding mother of an infant, my priorities were evolving differently than ever before in my career. Suddenly, to reduce the health risk to my family, the place I would most want to avoid was exactly where I was: the emergency room. After one shift spent balancing patient care and breast pumping, I started to feel sick with body aches, headache, and fever. I soon received a telephone call from my program director. A patient I had admitted a few days back without complete personal protective equipment, a sweet older lady with flu-like symptoms, turned out to be our county's first of now-many official coviD-19 patients. In the end, it turned out that my flu-like symptoms were attributable to an uncomplicated case of influenza, but my patient was not as lucky and succumbed to COVID-19 days later, connected to a ventilator in the intensive care unit, away from her family.

Kübler-Ross developed her theory based on certain human reactions occurring in a set order: denial, anger, depression, bargaining, and acceptance. After being hit by the COVID-19 pandemic, many of us are experiencing a sort of grieving, and I am no different.

\section{Denial}

I could not understand the speed with which things changed. One day, you have no imminent fears; the next, you are checking life insurance policies. In my heart, I selfishly did not want to be working with fears for my family, and yet altruistically, I knew that this was the life I had chosen. It was hard to bear thoughts of my life without seeing my son growing up. It made me think of my many young cancer patients who were taken away from their lives in similar life conditions, and it hurt more than ever before.

\begin{abstract}
Anger
I advocated for training residents to minimize their exposure to patients with known or possible COVID-19 infection because attending physicians would already have to assess patients themselves. I suddenly felt angry: angry that, since the pandemic started in the United States, we were all exposed in a war without adequate personal protective equipment; angry that the recommendations from the U.S. Centers for Disease Control and Prevention sounded so different from recommendations in other nations. My outrage grew as colleagues started to test positive for the disease throughout the country. I was worried about vulnerable house staff thrown into the unknown, while the Centers for Disease Control and Prevention had not released any official comments about exactly who the vulnerable populations were. It made me think of my cancer patients' anger when they asked me in exasperation "why cancer chose me" and "how will I be able and ready to deal with it"-questions that we are far from being able to answer as doctors.
\end{abstract}

\section{Depression}

I felt sad to see hard-working pregnant residents and residents with pregnant wives or elderly family members at home struggling through solutions on how to work, but still shield themselves and their families from COVID-19. I felt helpless when requests for hazard pay were not fulfilled for health care workers. I felt overwhelmed by the rituals of a new obsessive-compulsive behaviour of cleanliness all day long. I missed human contact and felt anxious when someone physically approached me. I feared breathing in front of my son, who joyfully pulled my masks away until I gave up on wearing them at home. I missed my family, worrying that I would not see them anytime soon or that something might happen to them. I thought of my cancer 
patients shrinking emotionally when they could not find the answers they were looking for and had to adapt to a new reality far from the life they had chosen for themselves.

\section{Bargaining}

I started to listen to and read about the experiences of others. I still had trouble understanding how some people could be so positive. I felt that they were naïve, but I started thinking that I should force myself to try a more positive approach as a way to escape the downslope of negativity the pandemic had brought with it. I was so busy working that I stopped thinking about the dying bodies in New York City, the refrigerated trucks outside the hospitals, or the beautiful parks turning into cemeteries. I was just living one day at a time, aiming to keep my patients safe as if they were my own family and to keep updating and encouraging families so that they felt as if their loved ones were not abandoned to their fates alone. We were all there for them, risking what was most precious for us: our lives and the lives of our families. In a similar way, this is a phase that cancer patients go through when they seek help from others. They build a community that helps them to hold on to one another and to find mechanisms to deal with their new reality so as to be as functional as possible, distancing their negative thoughts from their daily life.

\section{Acceptance}

I started to feel encouraged by positive changes made since the pandemic started. Our hospital was one of the first to remove vulnerable pregnant residents from direct contact with COVID-19 patients, and I felt proud about it. Resident exposure was being limited as much as possible. Free housing options were given to those in vulnerable personal or familial conditions. A team led by one of our residents developed massive production of masks and face shields to be distributed to nursing homes and small hospitals housing the most vulnerable populations without access to adequate personal protective equipment. Our brightest mentors from the intensive care, infectious diseases, and medicine teams were tirelessly giving their best to understand, navigate, and teach us all throughout these times, despite their own fears.

I started to find usefulness in my experience in oncology; I had close connections with the families of our patients with COVID-19 and experience in dealing with a devastating disease. For some cases in oncology and most of the severe cases of COVID-19, no effective treatment is available aside from ongoing clinical research. Our goal is to provide patients with dignity of living based on what that means for them: an individualized approach. I was not just offering technical medicine for patients with COVID-19 as a doctor. I was starting to feel as if I was making a difference in the lives of families by listening to them, understanding their backgrounds, and empathetically discussing their values and goals of care. I involved them in the decision-making processes together with the medical team, hoping for the best, but preparing for the worst that COVID-19 would bring. If the worst happened, many would opt for comfort measures instead of prolonged suffering caused by connection to a ventilator, tracheostomy, or hopeless rounds of cardiopulmonary resuscitation. I suddenly felt more alive, as if somehow the oncologist I have in me was back despite not seeing cancer patients-realizing that the human approach to, and understanding of, a disease with a poor prognosis does not, in general, differ despite different causes.

\section{SUMMARY}

Kübler-Ross became a guide for oncology and palliative care because of the tragic nature of cancer. She has helped health practitioners navigate the process of grief and develop a more caring and natural approach. Today, she has helped me understand, acknowledge, and advance my own reactions in an unfortunate time, regaining strength to continue to help others despite my own fears. She has also helped me think in a more personal way about cancer patients and explore other ways to help them more comprehensively in the future.

May her legacy persist for as long as humans are vulnerable to grief, reminding us all that mental and physical support to patients and providers are equally essential.

\section{ACKNOWLEDGMENTS}

This article reflects the first-person account of AMK. RA is her mentor at the University of Connecticut and reviewed the article for agreement with the institution's guidelines.

\section{CONFLICT OF INTEREST DISCLOSURES}

We have read and understood Current Oncology's policy on disclosing conflicts of interest, and we declare that we have none.

\section{AUTHOR AFFILIATIONS}

*University of Connecticut, Farmington, CT, U.S.A. 